\title{
Pengaruh Strategi Service Center Dalam Penanganan Komplain Terhadap Kepuasan Tamu Pada Resinda Hotel Karawang
}

\author{
Lia Kusdiana Sari ${ }^{1}$, Titik Akriningsih ${ }^{2}$, Basrawi Yudi Nugroho ${ }^{3}$ \\ ${ }^{1,2,3}$ Sekolah Tinggi Pariwisata Sahid Surakarta \\ ${ }^{3}$ Email; ai_RienNha82@yahoo.com
}

\begin{abstract}
The purpose of this study was to determine the Service Center strategy implemented by the Front Office department in handling complaints from guests at Resinda Hotel Karawan and to determine the effect of Service Center strategies in handling guest complaints on guest satisfaction at Resinda Hotel Karawang. This research method uses observation, interview, and documentation techniques. Population and sample consisted of 20 people including 1 General Manager, 1 Service Center Supervisor, 4 Duty Managers, 1 Service Center Staff and 13 Guests who have stayed overnight. Types of complaints that occur at the Service Center include complaints in writing or indirectly or verbally or directly. Tips for a hotel in carrying out a complaint handling strategy against guests so that guests feel satisfied while staying or using products / services at the hotel. Because hospitality is one of the accommodation facilities that provide lodging services, food and beverage services and other supporting services. This description shows the importance of how a hotel provides the best service for guests so that guests feel satisfied and have a sense of returning to the hotel. From this analysis, it can be seen that the Service Center strategy carried out by Resinda Hotel Karawang already has a set standard.
\end{abstract}

Keywords: Complaint Handling, Strategy, Guest Satisfaction, Service Center Article Information: Submission: 17 Juli 2021, Accepted: 04 Agustus 2021, Published: 10 Agustus 2021 DOI: - 


\section{PENDAHULUAN}

Hotel merupakan wadah yang menyediakan sarana tempat tinggal sementara (akomodasi) bagi umum, yaitu: Orang-orang yang datang dengan berbagai ragam tujuan, maksud serta keperluan ke daerah di mana hotel berdomisili. Hotel memilih domisilinya di tempat-tempat atau di lingkungan daerah yang memiliki potensi untuk dikunjungi, seperti panorama, adat istiadat masyarakat, sosial, budaya, sebagai pusat pemerintahan, pusat perdagangan, keagamaan dan pusat kegiatan spiritual dan lain-lain. Hotel sebagai tempat tinggal sementara harus dapat mencerminkan pola kebudayaan masyarakatnya dalam arti yang luas. Hotel diharapkan dapat mencerminkan suasana hunian yang dinamis, kreatif, serta dapat menciptakan suasana yang homogeny di tengahtengah suasana yang heterogen di daerah di mana hotel berlokasi.

Hotel merupakan usaha jasa pelayanan yang cukup rumit pengelolaannya, dengan menyediakan berbagai fasilitas yang dapat dipergunakan oleh tamu-tamunya selama 24 jam (untuk klasifikasi hotel berbintang 4 dan 5). Di samping itu, usaha perhotelan juga dapat menunjang kegiatan para usahawan yang sedang melakukan perjalanan usaha ataupun para wisatawan pada waktu melakukan perjalanan untuk mengunjungi daerah- daerah tujuan wisata, dan membutuhkan tempat untuk menginap, makan dan minum serta hiburan. Dan untuk lebih lanjut, area yang namun pada penelitian ini difokuskan pada Front Office saja khususnya pada bagian Service Center.

Front office berasal dari kata bahasa inggris "front" yang artinya depan, dan "office" artinya kantor. Jadi front office adalah kantor depan. Dalam konteks pengertian hotel, kantor depan merupakan sebuah departemen di hotel yang letaknya di bagian depan. Tepatnya tidak begitu jauh dari pintu depan hotel atau lobby. Area ini merupakan tempat yang paling sibuk di hotel. Dengan lokasinya dibagian paling depan maka front office termasuk departemen yang paling mudah dicari dan dilihat oleh tamu. Di dalam front office departmen dibagi menjadi beberapa bagian, salah satunya adalah service center (telepon operator) yang memiliki tugas untuk membantu tamu pada saat tamu membutuhkan sesuatu di dalam kamar ataupun pada saat tamu ada keluhan (complaint) melalui telepon.
Front Office Department atau Bagian Kantor Depan bagi hotel dikenal sebagai The first and the last impression of the guest, artinya di Front Office inilah yang pertama dan terakhir dari tamu. Tamu yang akan menginap di hotel akan datang dahulu ke bagian Front Office, dan pada waktu akan check-out pun tamu harus berhubungan dengan staf di Front Office. Jadi, dapat dikatakan bahwa kesan yang mendalam tamu terhadap hotel akan tercipta di bagian Front Office ini.

Service Center untuk mengurangi komplain supaya tamu merasa puas. Secara khusus hal ini sangat penting untuk menerapkan penanganan komplain menggunakan strategi Service Center yang tepat sehingga diharapkan tamu dapat merasakan pelayanan yang memuaskan terlebih lagi pada Resinda Hotel Karawang.

Berdasarkan latar belakang yang telah disampaikan di atas, maka penulis tertarik untuk melakukan penelitian dengan judul "PENGARUH STRATEGI SERVICE CENTER DALAM PENANGANAN KOMPLAIN TERHADAP KEPUASAN TAMU PADA RESINDA HOTEL KARAWANG".

Masalah yang sering dihadapi oleh seorang service center di Resinda Hotel Karawang biasanya berhubungan dengan keluhan tamu pada saat berada di dalam kamar. Adapun rumusan masalah yang penulis angkat adalah: apa saja strategi Service Center yang diterapkan pada Front Office department untuk menangani komplain dari para tamu di Resinda Hotel Karawang? Bagaimana pengaruh strategi Service Center dalam penanganan komplain terhadap kepuasan tamu pada Resinda Hotel Karawang?

Adapun tujuan dari kegiatan penelitian ini adalah sebagai berikut: Untuk mengetahui strategi Service Center yang diterapkan Front Office department dalam menangani komplain dari para tamu pada Resinda Hotel Karawang. Untuk mengetahui pengaruh strategi Service Center dalam menangani komplain tamu terhadap kepuasan tamu pada Resinda Hotel Karawang. 


\section{METODE PENELITIAN}

Penelitian yang dilakukan saat ini termasuk dalam jenis penelitian deskriptif (descriptive research) dengan menggunakan pendekatan kualitatif. Penelitian dilakukan di Resinda Hotel Karawang selama 6 bulan, yakni pada Agustus 2019 sampai dengan Januari 2020.

Populasi dalam penelitian ini adalah seluruh personel yang ada di Resinda Hotel Karawang dan tamu hotel yang pernah menginap. Melalui teknik Convinence Sampling, maka diperoleh sampel penelitian yang terdiri atas 7 Staff Resinda Hoter Karawang yang terdiri dari 1 orang General Manager dan 6 orang staf di bagian front office yang terdiri dari 4 orang sebagai Duty Manager, 1 orang Supervisor, 1 staf dibagian Service Center Resinda Hotel Karawang dan 13 orang tamu hotel.

Sumber data dalam penelitian ini terdiri atas data primer dan data sekunder. Data diperoleh melalui teknik pengumpulan data yang terdiri atas teknik observasi, wawancara, dan dokumentasi. Data yang diperoleh kemudian dianalisa menggunakan triangulasi sumber dan triangulasi teknik

\section{HASIL DAN PEMBAHASAN}

\section{Strategi Service Center Yang Diterapkan Pada Front Office Department Untuk Menangani Komplain Tamu Pada Resinda Hotel Karawang.}

Hal penting yang perlu dipahami sebelum mengetahui penerapan strategi Service Center dalam menangani komplain dari para tamu di Resinda Hotel Karawang adalah membagi jenis keluhan yang dirasakan dan disampaikan oleh para tamu. Secara detail, jenis keluhan yang disampaikan di Resinda Hotel Karawang adalah komplain secara langsung dan tidak langsung, antara lain:

\section{a. Keluhan Secara Lisan atau Keluhan Secara Langsung}

Keluhan langsung merupakan keluhan yang disampaikan secara langsung kepada pihak hotel mengenai perasaan tidak puas/pengalaman buruk yang diterima. Keluhan tersebut disampaikan melalui tatap muka maupun komunikasi menggunakan telepon dengan pihak hotel. Pada bagian Service Center Resinda Hotel Karawang, keluhan langsung dilakukan melalui telepon dan biasanya keluhan dari tamu tersebut akan segera di follow up oleh seorang Service Center agar permasalahan tersebut segera selesai dengan baik.

Jenis-jenis keluhan langsung yang diterima pihak Guest Service Center, antara lain: Keluhan atas produk/jenis layanan yang diberikan, Keluhan atas lambatnya pelayanan, Keluhan atas sikap staf atau karyawan, Keluhan atas fasilitas yang disediakan, dan Keluhan atas kebersihan dan kerapihan kamar dan area lain di dalam hotel.

\section{b. Keluhan Secara Tertulis atau Tidak Langsung}

Keluhan tidak langsungmerupakan keluhan yang disampaikan melalui lembar pengaduan/kotak saran/surel yang disediakan oleh hotel maupun melalui pihak ketiga seperti media massa atau pengacara. Pada Resinda Hotel Karawang keluhan secara tertulis atau tidak langsung dilakukan menggunakan form Guest Comment yang disediakan di kamar hotel, dan bisa melalui media sosial seperti komentar pada halaman website resmi Resinda Hotel Karawang atau Trip Advisor.

Jenis-jenis keluhan tidak langsung yang diterima pihak Guest Service Center, antara lain: Keluhan yang atas lambatnya pelayanan dan direview ke gest comment, Keluhan yang diutarakan tamu melalui tripadvisor mengenai ketidakpuasan fasilitas yang diberikan, dan Keluhan atas kualitas kamar yang diutarakan tamu di website resmi hotel. Secara spesifik, dalam menangani keluhan pihak Resinda Hotel Karawang memusatkan interaksi antara pihak hotel dengan tamu pada Guests Service Center. Hal ini mempermudah tamu dalam melakukan komplain karena Guests Service Center mampu menerima komplain selama 24 jam penuh, sehingga seluruh komplain dari berbagai departemen akan ditampung terlebih dahulu oleh bagian Guests Service Center sebelum diselesaikan atau diatasi oleh departemen yang terkait. Hal tersebut dilakukan agar tidak terjadi kesalahan dalam menangani keluhan tamu. Guests Service Center juga diwajibkan untuk memberikan tanggapan secara efektif atas komplain yang disampaikan tamu. Pihak Guests Service Center tidak boleh menjanjikan sesuatu kepada para tamu yang menyampaikan 
komplain maupun tidak boleh memberikan kepastian seperti yang diharapkan oleh para tamu.

Hal ini telah sesuai dengan hasil pengamatan yang dilakukan oleh peneliti pada saat melakukan observasi dan wawancara yang mewakili 20 sampel pada Resinda Hotel Karawang. Hasil pengamatan terkait hal tersebut sebagaimana dalam Lampiran 2, dimana bila terjadi hal-hal penting yang terjadi sehubungan dengan keluhan dari para tamu maka pihak Guests Service Center akan mencatat secara khusus. Berikut hasil observasi penerimaan pengaduan atau komplain dari para tamu, antara lain: Hasil pengamatan keluhan mengenai kesesuaian produk/jenis layanan yang diharapkan oleh para tamu di Resinda Hotel Karawang, selama peneliti melakukan penelitian tidak ditemukan adanya keluhan tersebut.

Adapun hasil pengamatan mengenai keluhan atas lambatnya pelayanan yang diberikan kepada tamu Resinda Hotel Karawang, antara lain berupa lamanya petugas House Keeper mengantar pesanan Hair Dryer yang tidak tersedia di kamar hotel.

Hasil pengamatan mengenai keluhan atas sikap staf atau karyawan di Resinda Hotel Karawang berupa komplain karena petugas tidak ramah, kurang senyum dan tidak mengucapkan greeting. Sedangkan hasil pengamatan mengenai keluhan terhadap fasilitas yang disediakan oleh Resinda Hotel Karawang, berupa televisi yang disediakan di dalam kamar tidak menyala dan shower kamar mandi yang tidak bisa dipakai.

Terakhir, hasil pengamatan mengenai keluhan atas kebersihan dan kerapihan kamar serta area lain di dalam Resinda Hotel Karawang, berupa bau kamar yang tidak sedap dan pengap serta dinding kamar berjamur. Adapun hasil wawancara terkait penerimaan pengaduan atau komplain dari para tamu, sebagaimana dijelaskan oleh Supervisor Service Center Emmi Samosir, sebagai berikut: "Di sini srategi Service Center yang dilakukan salah satunya yaitu memberikan service yang terbaik, sehingga tamu puas dan akan kembali lagi ke hotel kita. Selain itu kami juga meminta maaf terlebih dahulu kemudian mengusahakan untuk memberikan apa yang dia butuhkan.
Selanjutny memberikan pelayanan kepada tamu dengan baik dan biasanya memberikan good gesture seperti free upgrade atau free consume in restaurant." (Emmi Samosir, Supervisor Service Center Resinda Hotel Karawang, hasil wawancara tanggal 5 Desember 2019)

Sedangkan hasil wawancara terkait kesesuaian produk/jenis layanan yang diberikan menurut Emmi Samosir selaku Supervisor Service Center, sebagai berikut: "Sampai saat ini belum ada keluhan mengenai kesesuaian produk/ jenis layanan yang dianggap tidak memuaskan tamu." (Emmi Samosir, Supervisor Service Center Resinda Hotel Karawang, hasil wawancara tanggal 5 Desember 2019).

Hasil wawancara terkait lambatnya pelayanan yang diberikan kepada tamu, menurut Emmi Samosir selaku Supervisor Service Center, sebagai berikut:

"Kami pernah menerima keluhan atas lambatnya pelayanan berupa lamanya petugas House Keeper mengantar pesanan Hair Dryer yang tidak tersedia di kamar hotel. Kami menanganinya dengan menyampaikan pesan apa adanya secara berulang- ulang bahwa petugas kami sudah menindaklanjuti dan sedang menuju ke kamar tamu." (Emmi Samosir, Supervisor Service Center Resinda Hotel Karawang, hasil wawancara tanggal 5 Desember 2019).

Hasil wawancara terkait keluhan sikap staf yang dirasakan oleh tamu, menurut Emmi Samosir selaku Supervisor Service Center, sebagai berikut: "Menindaklanjuti mengenai keluhan atas sikap staf yang dinilai oleh tamu kurang ramah, kami menyampaikan kepada tamu permohonan maaf dan akan memperbaiki kesalahan mngenai sikap staf tersebut." (Emmi Samosir, Supervisor Service Center Resinda Hotel Karawang, hasil wawancara tanggal 5 Desember 2019)

Hasil wawancara terkait keluhan tentang fasilitas yang disediakan pihak hotel, menurut Emmi Samosir selaku Supervisor Service Center, sebagai berikut: "Menindaklanjuti keluhan tamu berupa Televisi yang tidak menyala, shower tidak bisa dipakai. Kami menanganinya dengan menyampaikan pesan apa adanya secara berulang- ulang bahwa 
petugas enggenering kami sudah menindaklanjuti dan sedang menuju ke kamar tamu untukmemperbaiki kerusakan pada fasilitas di dalam kamar tersebut" (Emmi Samosir, Supervisor Service Center Resinda Hotel Karawang, hasil wawancara tanggal 5 Desember 2019).

Hasil wawancara terkait kebersihan dan kerapihan kamar dan area lain di dalam Resinda Hotel Karawang, menurut Emmi Samosir selaku Supervisor Service Center, sebagai berikut: "kami pernah menerima keluhan berupa bau kamar yang kurang sedap dinding kamar berjamur, toilet bocor. Kami menanganinya dengan menyampaikan permintaan maaf, menyampaikan pesan apa adanya secara berulang- ulang bahwa petugas enggenering dan House Kepping kami sudah menindaklanjuti dan sedang menuju kekamar tamu untuk memperbaiki kerusakan dan membersihkanm kamar tersebut." (Emmi Samosir, Supervisor Service Center Resinda Hotel Karawang, hasil wawancara tanggal 5 Desember 2019).

Sedangkan hasil wawancara terkait penerimaan pengaduan atau komplain dari para tamu, sebagaimana dijelaskan oleh General Manager Ibu Ruth Hutapea, sebagai berikut: "Terkait pengaduan komplain oleh para tamu di Resinda Hotel Karawang, terjadi keluhan secara lisan maupun tertulis, sehingga suntuk menangani hal tersebut saya harus turun tangan untuk menindak lanjutinya agar kinerja staf Hotel bisa lebih baik dalam menjalankan SOP yang diberikan, serta memperbaiki atau menjaga citra Hotel tetap baik dimata para tamu yang akan maupun sudah menginap di Resinda Hotel Karawang." (Ruth Hutapea, General Manager Resinda Hotel Karawang, hasil wawancara tanggal 5 Desember 2019)

Sedangkan hasil wawancara terkait kesesuaian produk/jenis layanan yang diberikan menurut Ruth Hutapea, General Manager, sebagai berikut: "Untuk keluhan terkait kesesuaian produk/jenis layanan yang tidak sesuai dengan harapan tamu beberapa kerap terjadi di Resinda Hotel Karawang, tetapi keluhan tersebut biasanya terjadi pada bagian department back office yaitu sales marketing, untuk menangani hal tersebut saya memberi tahu tamu bagian yang menangani keluhannya dan jawaban mengenai keluan tersebut akan diberikan secepatnya. Dan setelah itu untuk menindaklanjuti hal tersebut saya akan meminta maaf kepada tamu serta mengevaluasi produk/jenis layanan yang tidak sesuai harapan tamu tersebut." (Ruth Hutapea, General Manager Resinda Hotel Karawang, hasil wawancara tanggal 5 Desember 2019).

Hasil wawancara terkait lambatnya pelayanan yang diberikan kepada tamu, menurut Ruth Hutapea, General Manager, sebagai berikut: "Di Hotel yang saya pimpin telah ada beberapa laporan mengenai keluhan atas lambatnya pelayanan berupa lamanya waktu saat tamu meminta sesuatu, atau saat tamu ingin check in dan check out, staf Front Office menangani dengan waktu yang kurang singkat. Jika staf Hotel tidak bisa menangani complain dengan baik, saya yang harus turun tangan menangani keluhan para tamu tersebut dengan mengikat perhtian para tamu serta mempengaruhi tamu sebelum tamu mengambil keputusan secara sepihak." (Ruth Hutapea, General Manager Resinda Hotel Karawang, hasil wawancara tanggal 5 Desember 2019).

Hasil wawancara terkait keluhan sikap staf yang dirasakan oleh tamu, menurut Ruth Hutapea, General Manager, sebagai berikut: "Menindaklanjuti staf yang sikap dan perilakunya kurang menyenangkan kepada tamu Hotel, saya kn menindaklanjuti dan menciptakan pemahaman dan keyakinan kepada tmu mengenai sikap staf Hotel yang dikeluhkan tersebut, mengenai keluhan atas sikap staf yang dinilai oleh tamu kurang, saya menyampaikan kepada tamu permohonan maaf atas ketidak nyamanannya. Kemudian saya memberikan informasi kepada departemen yang bersangkutan". (Ruth Hutapea, General Manager Resinda Hotel Karawang, hasil wawancara tanggal 5 Desember 2019).

Hasil wawancara terkait keluhan tentang fasilitas yang disediakan pihak hotel, menurut Ruth Hutapea, General Manager, sebagai berikut: "Menindaklanjuti keluhan tamu mengenai misalnya berupa Televisi yang tidak menyala, shower tidak bisa dipakai. Saya akan memberikan informasi apa adnys kepada tamu tersebut, serta memberikan 
pesan masukan terhadap staf department yang menangani hal tersebut agar sebisa mungkin tidak terjadi kesalahan yang sama, dan saya meminta permohonan maaf secara langsung kepada tamu dengan cara melalui email dan memberikan option untuk pindak kamar yang tidak terjadi kerusakan." (Ruth Hutapea, General Manager Resinda Hotel Karawang, hasil wawancara tanggal 5 Desember 2019).

Hasil wawancara terkait kebersihan dan kerapihan kamar dan area lain di dalam Resinda Hotel Karawang, menurut Ruth Hutapea, General Manager, sebagai berikut: "Menangani secara langsung mengenai keluhan tamu terhadap kebersihan kamar seperti, bau kamar yang kurang sedap dinding kamar berjamur, toilet bocor, dan saya selanjutnya akan melakukan tindakan cecara lngsung kepada staf hotel yang menangani hal tersebut serta kepada tamu agar tamu tidak menjadikan hal tersebut sebagai kesalahan yang berat sehingga tamu tidak akan memberikan review buruk nantinya setelah meninggalkan Hotel. Saya menindaklanjuti dengan tegas hal tersebut, memberikan perhatihan lebih kepada tamu yang memberikan keluhan. serta menanganinya dengan menyampaikan permintaan maaf, menyampaikan pesan apa adanya secara berulang-ulang bahwa petugas sudah menindaklanjuti dan sedang menuju ke kamar tamu untuk memperbaiki kerusakan dan membersihkan kamar tersebut." (Ruth Hutapea, General Manager Resinda. Hotel Karawang, hasil wawancara tanggal 5 Desember 2019)

Adapun hasil wawancara kepada tamu Resinda Hotel Karawang terkait pengaduan atau komplain kepada petugas atau staf Service Center, sebagaimana dijelaskan oleh beberapa tamu Resinda Hotel Karawang, sebagai berikut:

Hasil wawancara terkait pelayanan di Resinda Hotel Karawang, menurut Bapak Reza T, sebagai berikut: "keluhan mengenai kecepatan dalam melayani pelanggan salah satu contoh saat tamu meminta request hair dryer kepada Petugas Service Center, tetapi pihak dari Housekeeping tidak segera menuju ke kamr tamu”. (Bapak Reza T, Tamu
Resinda Hotel Karawang, 12 Januari 2020). Hasil wawancara terkait keluhan sikap staf yang dirasakan oleh Bapak Heru Setia Budi selaku tamu di Resinda Hotel Karawang, sebagai berikut: "keluhan atas sikap staf yang dinilai oleh tamu kurang ramah, dan penampilan karyawan yang tidak sesuai harapan seperti penampilan tidak rapi layknya seorang Hotelier". (Bapak Heru Setia Budi, Tamu Resinda Hotel Karawang, 10 Januari 2020).

Hasil wawancara terkait keluhan tentang fasilitas yang disediakan pihak hotel, menurut Ibu Bunga Permana selaku tamu Resinda Hotel Karawang, sebagai berikut: "keluhan mengenai fasilitas dan peralatan yang tidak memenuhi kebersihan dan kerapihan sert tidakmemenuhi sesuai harapan”. (Ibu Bunga Permana, Tamu Resinda Hotel Karawang, 4 Januari 2020).

Hasil wawancara terkait kebersihan dan kerapihan kamar dan area lain di dalam Resinda Hotel Karawang, menurut Ibu Endang Srikayati, sebagai tamu Resinda Hotel Karawang, sebagai berikut: "Keluhan mengeni kebersihan di kamar berupa bau kamar yang kurang sedap dinding kamar berjamur, toilet bocor". (Ibu Bunga Permana, Tamu Resinda Hotel Karawang, 8 Januari 2020)

Hasil dokumentasi terkait penerimaan pengaduan atau komplain dari para tamu sebagaimana keluhan yang sampaikan melalui Guest Comment, TripAdvisor dan Google Search/Website.



Gambar 1. Komplain Tamu Melalui TripAdvisor 


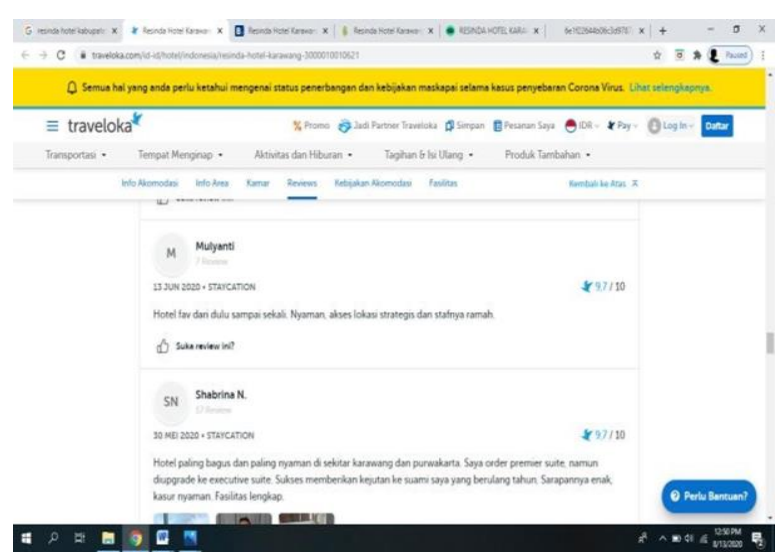

Gambar 2. Komplain Tamu Melalui Google Search/Website



Gambar 3. Komplain Tamu Melalui Guest Comment

Berdasarkan hasil pengamatan, wawancara dan dokumentasi yang diperoleh dalam penelitian ini, maka dapat diketahui bahwa strategi yang diterapkan oleh Service Center dalam menangani keluhan dari para tamu agar tercipta kepuasan tamu antara lain dilakukan dengan Strategi Informatif, Redundancy, Koersif.

\section{Pengaruh Strategi Service Center Dalam Penanganan Komplain Terhadap Kepuasan Tamu Pada Resinda Hotel Karawang}

Berdasarkan hasil penelitian di atas, dikatakan bahwa pihak menejemen Resinda Hotel Karawang sudah menerapkan strategi
Informatif, raedundancy, dan Koersif. Dampak dari penerapan strategi informatif sangat dirasakan oleh tamu berupa adanya kejelasan atu penyampaian keterangan yang sebenarnya sebagai sehingga tamu biasa menerima informasi yang sesuai fakta dan dapat di terima dengan puas. Adapun penerpan strategi Redudancy yaitu berupa mengulang-ulang pesan kepada tamu, sehingga tamu dapat menerima pesan dengan benar dengan apa yang disampaikan sebelumnya. Sedangkan pengaruh penerapan strategi Koersif yaitu berupa menginformasikan peraturan dan perintah kepada petugas hotel kepada tamu agar tamu tau dan bisa lebih nyaman dengan informasi yang diberikan.

\section{Implikasi Hasil Penelitian}

1. Strategi Service Center yang Diterapkan Pada Front Office Department Untuk Menangani Komplain Tamu Pada Resinda Hotel Karawang

Data yaitu observasi, Berdasarkan dari hasil penelitian yang dibuat penulis di Resinda Hotel Karawang melalui teknik pengumpulan wawancara, studi pustaka, dan dokumentasi diperoleh data dalam uraian kalimat, mengenai strategi service center yang diterapkan pada front office department untuk menangani komplain tamu pada resinda hotel karawang, yang peneliti dapatkan agar hasil penelitian dapat diimplikasikan oleh pengelola hotel khususnya di Resinda Hotel Karawang, untuk meningkatkan kualitas pelayanan terhadap tamu berkaitan dengan komunikasi dan informasi, mengingat faktor tersebut sangat berpengaruh dalam memberikan image positif terhadap tamu yang menginap di Resinda Hotel Karawang. Dan dapat dijadikan pedoman menarik untuk menambah jumlah occupancy tamu yang menginap di hotel. Hal ini sesuai dengan pendapat para tamu yang menginap di Resinda Hotel Karawang, dan merupakan faktor penting untuk mempengaruhi minat tamu untuk menginap dikemudian hari. Kemudian setelah diadakannya analisa data yang dilakukan lalu membandingkan dengan teori yang ada, menurut pandangan para ahli tentang pengertian keluhan pelanggan diantaranya adalah sebagai berikut: 
a. Pengertian keluhan pelanggan menurut Bell \& Luddington (2006) menyebutkan bahwa keluhan pelanggan (customer complaints) adalah umpan balik (feedback) dari pelanggan yang ditunjukkan kepada perusahaan yang cenderung bersifat negatif. Umpan balik ini dapat dilakukan secara tertulis atau secara lisan.

b. Pengertian keluhan pelanggan menurut Kotler (2005) bahwa keluhan pelanggan adalah bentuk aspirasi pelanggan yang terjadi karena adanya ketidakpuasan terhadap suatu barang atau jasa. Macam- macam keluhan pelanggan pada dasarnya terbagi 2 yakni keluhan yang disampaikan lewat lisan dan keluhan yang disampaikan secara tertulis.

\section{Pengaruh Strategi Service Center Dalam Penanganan Komplain Terhadap Kepuasan Tamu Pada Resinda Hotel Karawang}

Berdasarkan dari hasil penelitian yang dibuat oleh penulis di Resinda Hotel Karawang melalui teknik pengumpulan data yaitu observasi, wawancara, studi pustaka, dan dokumentasi diperoleh data dalam uraian kalimat, mengenai Pengruh Strategi Service Center Dalam Penanganan Komplain Terhadap Kepuasan Tamu Pada Resinda Hotel Karawang, yang peneliti dapatkan agar hasil penelitian dapat diimplikasikan oleh pengelola hotel khususnya di Resinda Hotel Karawang, untuk meningkatkan kualitas pelayanan terhadap tamu berkaitan dengan komunikasi dan informasi, mengingat faktor tersebut sangat berpengaruh dalam memberikan image positif terhadap tamu yang menginap di Resinda Hotel Karawang. Dan dapat dijadikan pedoman menarik untuk menambah jumlah occupancy tamu yang menginap di hotel. Hal ini sesuai dengan pendapat para tamu yang menginap di Resinda Hotel Karawang, dan merupakan faktor penting untuk mempengaruhi minat tamu untuk menginap dikemudian hari.

Kemudian setelah diadakannya analisa data yang dilakukan lalu membandingkan dengan teori yang ada, Menurut Engel et al, (1995) menyebutkan bahwa kepuasan dapat digambarkan sebagai evaluasi konsumsi pada alternatif yang dipilih, setidaknya memenuhi/melebihi harapan. Apabila tamu puas, kemungkinan besar akan menggunakan produk atau jasa yang sama. Kepuasan tamu juga cenderung akan memberikan referensi yang baik terhadap prospek yang dikenalnya. Namun sebaliknya, tamu yang tidak puas akan mengeluh dan menceritakan pengalaman buruknya kepada orang lain, atau secara ekstrim akan mengajukan gugatan hukum terhadap organisasi. Hal ini harus dicermati oleh suatu Hotel karena berbagai keluhan tersebut dapat menurunkan loyalitas tamu terhadap pelayanan yang diberikan. Dengan mendengarkan keluhan dari para tam, Hotel dituntut dapat menciptakan berbagai kebijaksanaan untuk mengatasi keluhan tersebut sehingga para tamu tidak beralih. Kunci dari semua itu adalah bagaimana mendorong para tamu untuk mengutarakan ketidakpuasannya kepada suatu Hotel.

\section{KESIMPULAN DAN SARAN Simpulan}

Berdasarkan hasil penelitian yang telah diperoleh penulis, maka penulis memperoleh kesimpulan sebagai berikut:

a) Strategi yang diterapkan pada Resinda Hotel Karawang antara lain Repetition, Informatif, Koersif.

b) Pengaruh strategi Service Center dalam dalam menangani komplain tamu yaitu tamu merasa lebih puas denga pelayanan yang diberikan, akan memperbaiki citra hotel, mutu serta nilai dari Resinda Hotel Karawang. Meningkatkan pelayanan Resinda Hotel Karawang berupa pelayanan informasi, penanganan komplain, pelayanan wake up call, petugas Service Center bersikap sopan dan ramah, cepat dalam memberi informasi, tepat dan dapat dipercaya kebenarannya sesuai dengan keinginan tamu

\section{Saran}

Berdasarkan kesimpulan diatas yang dilakukan selama penelitian, maka penulis memberikan saran bagi Resinda Hotel Karawang sebagai berikut:

a) Peneliti menganggap pentingnya memilih sumber daya manusia dan menjalankan SOP dengan benar dalam membangun citra Hotel, oleh sebab itu dalam memlakukan pekerjaan tepatnya di Service Center perlu dilakukan adanya briefing guna mengobservasibarbagai permasalahan dan penanganan keluhan terhadap tamu, khususnya yang menjadi objek dalam penelitian penulis kaitannya dengan 
mengenai pelayanan informasi dan komunikasi.

b) Dalam menggunakan strategi di Service Center guna memberikan pelayanan yang lebuh baik kepada tamu sebaiknya digunakan 6 strategi yang terdapat dalam strategi komunikasi antara lain Canalizing, Persuasif, Edukatif, Repetition, Informatif, Koersif. Agar penanganan komplain di Service Center pada Resinda Hotel Karawang dapat lebih maksimal dan dapat diatasi dengan baik.

\section{Daftar Pustaka}

Anwar Prabu Mangkunegara. 2001, Manajemen sumber daya manusia perusahaan, Bandung: Remaja Rosdakarya.

Arifin, Anwar. 1984. Strategi Komunikasi Sebuah Pengantar Ringkas, Bandung: ARMICO

Arifin, Anwar. 1994. Strategi Komunikasi: Sebuah Pengantar Ringkas. Bandung: Armico.

Arikunto, S. 1998. Prosedur Penelitian Suatu Pendekatan Praktek.

Cetakan ke-11. Jakarta: PT Rineka Cipta. Hlm: 67, 225.

Arikunto, S. 2010. Prosedur Penelitian Suatu Pendekatan Praktik. Jakarta: Rineka Cipta.

Bagyono. 2012. Teori\&Praktik Hotel Front Office. Bandung : CV. Alfabeta

Kualitatif). Jakarta: GP Press.

Bell, Simon J dan Luddington, James A. 2006. Coping With Customer Complaints. Journal of Service Research

De Vito, J.A., 2007, Komunikasi Antar Manusia, (terjemahan: Agus Maulana). Jakarta: Professional Books.

Effendy, Onong Uchjana. 2008. Dinamika Komunikasi. Bandung: PT. Remaja Rosdakarya.

Effendy, Onong Uchjana. 1990. Ilmu Komunikasi Teori dan Praktek. Bandung: PT. Remaja Rosda karya.

Ghozali, Imam. 2013. Aplikasi Analisis Multivariant dengan Program IBM SPSS. Edisi Semarang: Penerbit Universita Diponegoro.

Hasan Ali. 2013. Marketing dan Kasus - kasus pilihan. Jakarta: Center Academi Publishing Service
Kothari, C.R. 2004. Research Methodology Methods and Techniques, Second Revised Edition, New Age International (P) Ltd., Publishers. New Delhi.

Kotler, Philip, Manajemen Pemasaran Analisis, Perencanaan, Implementasi, dan Pengendalian, Alih Bahasa, Ancella Anitawati

Hermawan, Salemba Empat, Jakarta, 1995.

Kotler, Philip. 2003. Manajemen Pemasaran. Edisi kesebelas, Jakarta: Indeks kelompok Gramedia.

Kotler, Philip. 2005, Manajemen Pemasaran, Jilid I dan II, PT. Indeks, Jakarta

Kotler, Philip. \& Keller. 2012. Manajemen Pemasaran. Edisi 12. Jakarta: Erlangga

Moleong, Lexy.J., 2010. Metodologi Penelitian Kualitatif, Bandung: Remaja, Rosdakarya.

Moleong, Lexy J. 2004. Metodologi Penelitian Kualitatif. Bandung: Remaja Rosda Karya.

Riduwan, \& Lestari, T. 1997. Populasi dan Sampel. Bandung: Alfabeta

Sekaran, U. 2011. Research Methods, for Business. Jakarta: Salemba Embat.

Sondang P. Siagian. 1985, Administrasi Pembangunan, Jakarta: Bumi Aksara.

Sugiyono. 1997. Metodologi Penelitian Bisnis. Bandung: CV Alfabeta.

Sugiyono. 2006. Metode Penelitian Kuantitatif, Kualitatif dan R \& D. Bandung: Alfabeta.

Sugiyono. 2011. Metode Penelitian Kuantitatif, Kualitatif dan R\&D. Bandung: Afabeta

Sugiyono. 2013. Metode Penelitian Kualitatif, dan $\mathrm{R} \& \mathrm{D}$

Sugiyono. 2013. Metodologi Penelitian Kuantitatif, Kualitatif dan R\&D. Bandung: Alfabeta.CV.

Sugiyono. 2005. Memahami Penelitian Kualitatif. Bandung: ALFABETA

Suharno. 2007. Kualitas Pelayanan Hotel Graha Cakra Malang Jawa Timur Berdasrkan Kepuasan Konsumen. Thesis S2 UGM.

Sutaryo, 2005, Sosiologi Komunikasi, Yogyakarta: Arti Bumi Intaran.

Trisninawati. 2019. Peningkatan Mutu Pelayanan dan Restaurant Dalam Meningkatkan Kepuasan Konsumen di Azza Hotel Palembang 
Waty. 2010. Pengaruh Kualitas Pelayanan Terhadap Kepuasan Pelanggan di Hotel Dana Solo.

Wiyati, Eni Kardi, 2011. Peran Komunikasi dalam Pembangunan ModalSosial dan Kelembagaan, dalam Buku Jurnal Ilmu KomunikasiSekarang dan Tantangan Masa Depan. Jakarta: Kencana. Ed. 1. Cet. $1 ; x v i i i$.

www.BookBoon.com,2014

www.resindahotel.com

Zeithaml, V.A., M.J. Bitner, D.D. Gremler. 2013. Services Marketing: Integrating Customer Focus Across the Firm 6 thed. Mc.GrawHill. Boston 